ARTICLE

\title{
Reactions of $\mathrm{CO}_{2}$ and ethane enable $\mathrm{CO}$ bond insertion for production of C3 oxygenates
}

\author{
Zhenhua Xie ${ }^{1,2,8}$, Yuanguo Xü,3,8, Meng Xie ${ }^{2,4,8}$, Xiaobo Chen $^{5}$, Ji Hoon Lee ${ }^{2}$, Eli Stavitski ${ }^{6}$, \\ Shyam Kattel (10 ${ }^{7 凶} \&$ Jingguang G. Chen (1) ${ }^{1,2}{ }^{\infty}$
}

Reacting $\mathrm{CO}_{2}$ and ethane to synthesize value-added oxygenate molecules represents opportunities to simultaneously reduce $\mathrm{CO}_{2}$ emissions and upgrade underutilized ethane in shale gas. Herein, we propose a strategy to produce $\mathrm{C} 3$ oxygenates using a tandem reactor. This strategy is achieved with a $\mathrm{Fe}_{3} \mathrm{Ni}_{1} / \mathrm{CeO}_{2}$ catalyst (first reactor at $600-800^{\circ} \mathrm{C}$ ) for $\mathrm{CO}_{2}-$ assisted dehydrogenation and reforming of ethane to produce ethylene, $\mathrm{CO}$, and $\mathrm{H}_{2}$, and a $\mathrm{RhCo} / \mathrm{MCM}-41$ catalyst (second reactor at $200^{\circ} \mathrm{C}$ ) enabling $\mathrm{CO}$ insertion for the production of C3 oxygenates (propanal and 1-propanol) via the heterogeneous hydroformylation reaction at ambient pressure. In-situ characterization using synchrotron spectroscopies and density functional theory (DFT) calculations reveal the effect of Rh-Co bimetallic formation in facilitating the production of $\mathrm{C} 3$ oxygenates. The proposed strategy provides an opportunity for upgrading light alkanes in shale gas by reacting with $\mathrm{CO}_{2}$ to produce aldehydes and alcohols.

\footnotetext{
${ }^{1}$ Chemistry Division, Brookhaven National Laboratory, Upton, NY 11973, USA. ${ }^{2}$ Department of Chemical Engineering, Columbia University, New York, NY 10027, USA. ${ }^{3}$ School of Chemistry and Chemical Engineering, Jiangsu University, Zhenjiang 212013, China. ${ }^{4}$ School of Pharmacy, Jiangsu University, Zhenjiang 212013, China. ${ }^{5}$ Department of Mechanical Engineering, State University of New York at Binghamton, NY 13902, USA. ${ }^{6}$ National Synchrotron Light Source-II, Brookhaven National Laboratory, Upton, NY 11973, USA. 7 Department of Physics, Florida A\&M University, Tallahassee, FL 32307, USA.

${ }^{8}$ These authors contributed equally: Zhenhua Xie, Yuanguo Xu, Meng Xie. ${ }^{凶}$ email: shyam.kattel@famu.edu; jgchen@columbia.edu
} 
$n$ recent decades, increasing anthropogenic $\mathrm{CO}_{2}$ emissions ${ }^{1-3}$ and verified huge shale gas reserves ${ }^{4,5}$ have led to studies of effective ways of utilizing these molecules for synthesis of value-added chemicals. The catalytic reduction of $\mathrm{CO}_{2}$ by light alkanes (methane, ethane, propane, etc.) has been the subject of many investigations due to its promising role in mitigating $\mathrm{CO}_{2}$ emissions and producing chemical intermediates, such as syngas $\left(\mathrm{CO}+\mathrm{H}_{2}\right)^{6-11}$, alkenes $9,10,12,13$, and aromatics ${ }^{13,14}$. However, there is a lack of feasible strategy to produce oxygenates directly from $\mathrm{CO}_{2}$ and shale gas. Oxygenates (e.g., aldehyde and alcohol) are important chemicals and feedstocks widely used in the automotive, fine chemical, and pharmaceutical industries ${ }^{15,16}$. Thus, it is highly appealing to develop an effective strategy that enables the production of oxygenates by directly inserting CO moiety from $\mathrm{CO}_{2}$ into alkenes generated from shale gas.

Traditional hydroformylation, known as an important oxosynthesis route ${ }^{17-19}$, could be used as an important bridge to achieve the production of oxygenates from $\mathrm{CO}_{2}$ and shale gas. It involves the addition of syngas to alkenes to produce aldehydes and/or alcohols with $100 \%$ atom efficiency ${ }^{20}$. Syngas can be derived from natural gas, naphtha, or coal by partial oxidation or steam reforming ${ }^{21,22}$. Alkenes are typically produced from the partially oxidative cracking of naphtha or alkanes ${ }^{23,24}$. However, the transportation and storage of the highly toxic syngas and flammable alkenes raise potential safety risks ${ }^{21,22}$. Such drawbacks of the traditional hydroformylation process could be avoided if the feedstocks (alkenes and syngas) produced from the upstream reactor can be directly used for the downstream hydroformylation reaction, i.e., the tandem reactor strategy as shown in Fig. 1.

It has been identified that the catalytic reduction of $\mathrm{CO}_{2}$ by ethane (the second most abundant component in shale gas) can proceed with either dry reforming (via $\mathrm{C}-\mathrm{C}$ bond cleavage) to generate syngas or oxidative dehydrogenation (via $\mathrm{C}-\mathrm{H}$ bond cleavage) to yield ethylene ${ }^{11}$. Depending on catalyst properties and reaction conditions, the ratio of ethylene/syngas could be tuned $^{6}$, making it possible to use the product mixture as reactants to produce $\mathrm{C} 3$ oxygenates (propanal and 1-propanol) from $\mathrm{CO}_{2}$ and ethane via the strategy illustrated in Fig. 1.

Compared with the traditional high-pressure homogenous hydroformylation, the proposed strategy would benefit by carrying out reactions at ambient pressure, as illustrated by the thermodynamic analysis of C3 oxygenates at different pressures in Supplementary Fig. 1. This in turn requires efficient heterogeneous catalysts for both reactions to promote the formation of $\mathrm{C} 3$ oxygenates. Non-precious $\mathrm{FeNi} / \mathrm{CeO}_{2}$ catalyst is a good candidate for step (I) due to its role in readily tuning ethylene/syngas ratio using $\mathrm{Fe}_{x} / \mathrm{Ni}_{y}$ catalysts with different stoichiometries ${ }^{6}$. Different from the ligand complexes used in the traditional homogeneous hydroformylation catalysis, supported metal catalysts should be used for the heterogeneous reaction in step (II). Several previous studies have revealed that $\mathrm{Rh}, \mathrm{Co}$, and their bimetallic are the most promising catalysts $21,22,25,26$. However, it is not clear how these catalysts would perform in the tandem configuration

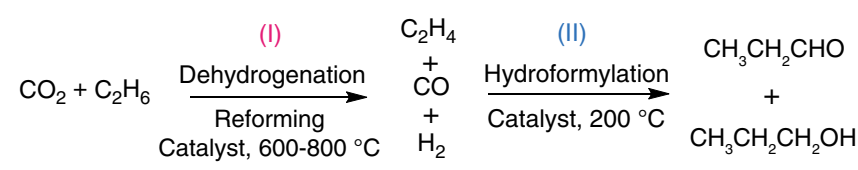

Fig. 1 Reaction scheme of the production of C3 oxygenates from the upgrading of $\mathrm{CO}_{2}$ and ethane. Ethylene and syngas are produced from the first reactor via the $\mathrm{CO}_{2}$-assisted dehydrogenation and reforming of ethane and subsequently used for the hydroformylation reaction in the second reactor to produce propanal and/or 1-propanol. with the hydroformylation feeds being directly generated from the reaction of $\mathrm{CO}_{2}$ and ethane.

In the present work, we explore the possibility of achieving the strategy to produce $\mathrm{C} 3$ oxygenates from $\mathrm{CO}_{2}$ and ethane. The experimental conditions are first identified using thermodynamic analyses for promising equilibrium conversions of $\mathrm{CO}_{2}$ and ethane into $\mathrm{C} 3$ oxygenates. Then, experiments with a tandem reactor validate the feasibility of the proposed reaction strategy using the combination of $\mathrm{Fe}_{3} \mathrm{Ni}_{1} / \mathrm{CeO}_{2}$ and $\mathrm{Rh}$-based catalysts supported on a high surface area MCM-41 substrate. Finally, insitu characterizations and density functional theory (DFT) calculations unravel the role of Co species in modifying the structural and electric properties of $\mathrm{Rh}$, enhancing the formation of $\mathrm{C} 3$ oxygenates.

\section{Results}

Thermodynamic analyses of reactions at ambient pressure. Figure $2 \mathrm{a}$ shows that the direct conversion of ethane and $\mathrm{CO}_{2}$ into propanal is unfavorable with a highly positive $\Delta G^{0}$ (purple line). However, it could be achieved using an alternative strategy as shown in Fig. 1 by dividing the overall reaction into two cascade steps: (I) production of ethylene and syngas and (II) subsequent hydroformylation. Figure $2 \mathrm{a}$ also shows that both dehydrogenation (blue and black lines) and reforming (red line) of ethane are favorable at high temperatures. In contrast, the hydroformylation of ethylene (golden line) thermodynamically prefers to occur at low temperatures. As a result, there is a thermodynamic gap between steps (I) and (II), which can be bridged using a tandem reactor to run each step within respective favorable temperature regions. To explore the feasibility of this hypothesis, equilibrium analyses were carried out at atmospheric pressure at different temperatures. As illustrated in Fig. 2b, the equilibrium distribution of products strongly depends on the temperature of the first reactor $\left(\mathrm{C}_{2} \mathrm{H}_{6}+\mathrm{CO}_{2}\right)$ : syngas is the dominant product below $600{ }^{\circ} \mathrm{C}$, whereas $\mathrm{C}_{2} \mathrm{H}_{4}$ becomes comparable with syngas at above $700^{\circ} \mathrm{C}$. Subsequently, the equilibrium products (mainly $\mathrm{CO}, \mathrm{H}_{2}$, and $\mathrm{C}_{2} \mathrm{H}_{4}$ ) from the first reactor obtained at different temperatures are used as the feed for the hydroformylation reaction in the second reactor $\left(200{ }^{\circ} \mathrm{C}\right)$. Figure $2 \mathrm{c}$ shows that the second reactor can yield $7-55 \%$ of oxygenates (propanal and 1-propanol) as the first reactor (feed ratio of $\mathrm{C}_{2} \mathrm{H}_{6} / \mathrm{CO}_{2}=1 \mathrm{~mol} / 0.5 \mathrm{~mol}$ ) is maintained from $600{ }^{\circ} \mathrm{C}$ to $1000{ }^{\circ} \mathrm{C}$.

Catalytic performance tests with single and tandem reactors. Based on the thermodynamic analyses, flow reactor experiments were performed using a tandem reactor configuration: first reactor $\left(600-850^{\circ} \mathrm{C}\right)$ loaded with $\mathrm{Fe}_{3} \mathrm{Ni}_{1} / \mathrm{CeO}_{2}$; second reactor $\left(200^{\circ} \mathrm{C}\right)$ loaded with $\mathrm{Rh}$-based catalysts. Figure $3 \mathrm{a}$ shows that distributions of $\mathrm{C}_{2} \mathrm{H}_{4}, \mathrm{CO}$, and $\mathrm{H}_{2}$ from the first reactor strongly depended on the temperature. Below $700{ }^{\circ} \mathrm{C}$, the production of $\mathrm{C}_{2} \mathrm{H}_{4}$ was negligible compared with that of syngas. At $750{ }^{\circ} \mathrm{C}$ and above, the $\mathrm{C}_{2} \mathrm{H}_{4} / \mathrm{CO} / \mathrm{H}_{2}$ ratio approached to a typical hydroformylation feed ratio $(1: 1: 1)$. As for the second reactor, using pure feed of $\mathrm{C}_{2} \mathrm{H}_{4}, \mathrm{CO}$, and $\mathrm{H}_{2}$, Fig. $3 \mathrm{~b}$ and Supplementary Table 2 illustrate that as the $\mathrm{Co} / \mathrm{Rh}$ bimetallic ratio increased, the yield of oxygenates increased from $2.4 \%$ on $\mathrm{Rh} / \mathrm{MCM}-41$ to $13.2 \%$ and $16.9 \%$ on $\mathrm{Rh}_{1} \mathrm{Co}_{1} / \mathrm{MCM}-41$ and $\mathrm{Rh}_{1} \mathrm{Co}_{3} / \mathrm{MCM}-41$, respectively. Moreover, the selectivity of 1-propanol also increased and even became comparable with propanal (15.8\% vs. $16.5 \%)$ on $\mathrm{Rh}_{1} \mathrm{Co}_{3} / \mathrm{MCM}-41$, offering a way to control the alcohol/aldehyde ratio. In addition, the oxygenate selectivity could also be affected by temperature that $42.5 \%$ of propanal was obtained on $\mathrm{Rh}_{1} \mathrm{Co}_{3} / \mathrm{MCM}-41$ at $180^{\circ} \mathrm{C}$ (denoted as $\mathrm{Rh}_{1} \mathrm{Co}_{3} *$ in Fig. 3b). As indicated by the Supplementary Table 2 and 
a

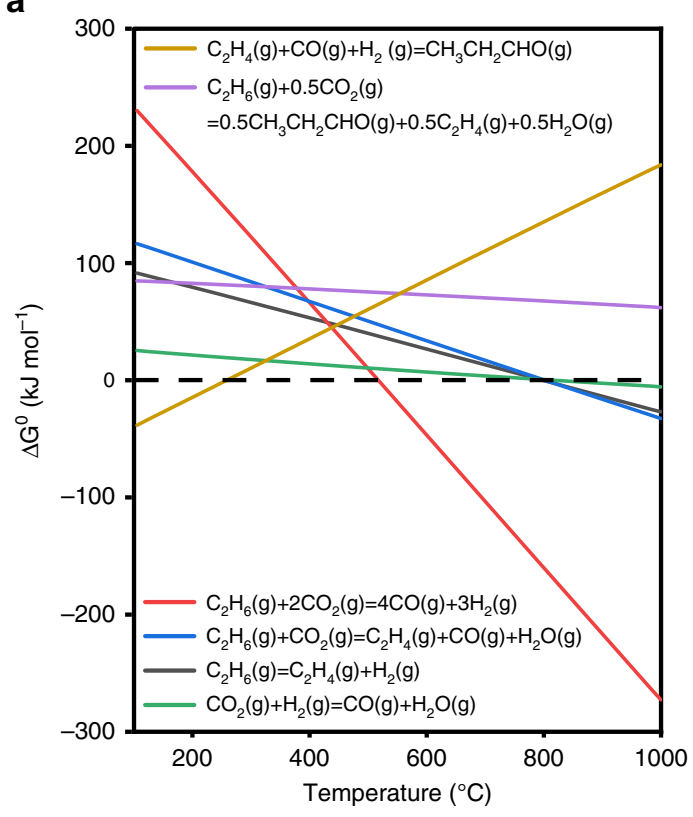

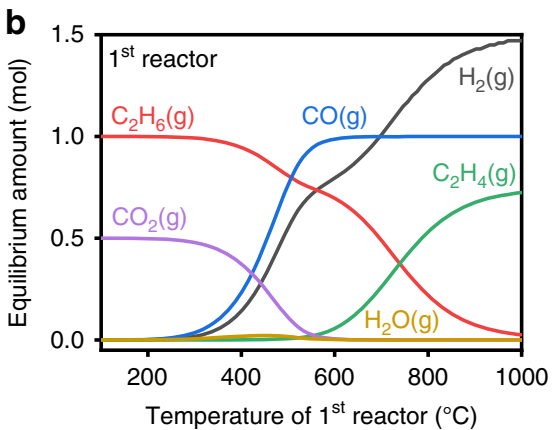

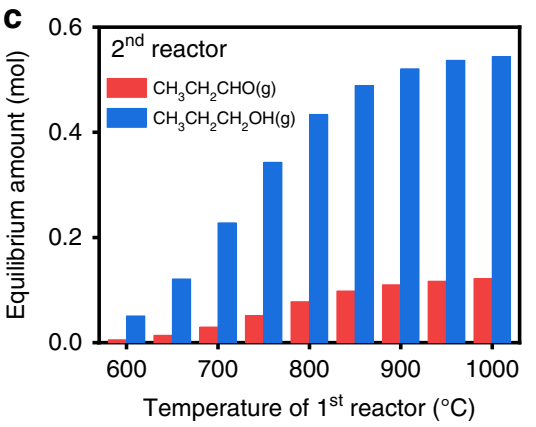

Fig. 2 Thermodynamic analyses of the proposed reaction strategy at the atmospheric pressure. a Diagram of standard Gibbs free energy change $\left(\Delta G^{0}\right)$ of involving reactions along with temperature. $\mathbf{b}$ Equilibrium species distribution as a function of temperature within the first reactor (feed ratio of $\mathrm{C}_{2} \mathrm{H}_{6} /$ $\mathrm{CO}_{2}=1 \mathrm{~mol} / 0.5 \mathrm{~mol}$ ). c Equilibrium amount of $\mathrm{C} 3$ oxygenates (propanal and 1-propanol) formed at $200^{\circ} \mathrm{C}$ within the second reactor using the products of the first reactor, which is maintained within the temperature range of $600-1000^{\circ} \mathrm{C}$. All the thermodynamics were calculated with $\mathrm{HSC}$ Chemistry 6.0 .

Supplementary Figs. 3-6, the measured propanal/1-propanol ratios in the second reactor were above 1.0 , higher than the equilibrium ratio of 0.26 at $200{ }^{\circ} \mathrm{C}$ (Supplementary Fig. 15), indicating that the interconversion between propanal and 1propanol did not reach equilibrium. For the tandem reactor configuration in Fig. 3c, C3 oxygenates were detected on the $\mathrm{Rh}_{1} \mathrm{Co}_{x} / \mathrm{MCM}-41$ catalysts as the first reactor ran at above $600{ }^{\circ} \mathrm{C}$. Control experiments with MCM-41, quartz sand, and blank tubing exhibited negligible oxygenates production (Supplementary Table 2-4). The highest yield of $\mathrm{C} 3$ oxygenates $(\sim 4.7 \%)$ was achieved by using the $\mathrm{Fe}_{3} \mathrm{Ni}_{1} / \mathrm{CeO}_{2}$ (at $800^{\circ} \mathrm{C}$ ) and $\mathrm{Rh}_{1} \mathrm{Co}_{3} / \mathrm{MCM}-41$ (at $200^{\circ} \mathrm{C}$ ) catalysts. As shown in Supplementary Fig. 7, a further increase in the C3 oxygenate yield toward $7.2 \%$ could be achieved by increasing the catalyst loading and modifying the reaction conditions. In addition, the durability of the $\mathrm{Fe}_{3} \mathrm{Ni}_{1} / \mathrm{CeO}_{2}$ catalyst, within the testing period of $31 \mathrm{~h}$ (Supplementary Fig. 8), indicated a stable feed supply for the downstream reactor. These results validate the feasibility of using the tandem reactor configuration to convert $\mathrm{CO}_{2}$ and ethane into $\mathrm{C} 3$ oxygenates.

It is noted that the values for conversion, turnover frequency (TOF), and oxygenates yield (Supplementary Figs. 2-6 and Supplementary Table 2) over $\mathrm{Rh}_{1} \mathrm{Co}_{3} / \mathrm{MCM}-41$ were higher than the sum of that of $\mathrm{Rh} / \mathrm{MCM}-41$ and $\mathrm{Co}_{3} / \mathrm{MCM}-41$, indicating a synergistic effect between $\mathrm{Rh}$ and $\mathrm{Co}$ in the bimetallic catalysts. To elucidate the origin of such effect, the metal particle size distributions were obtained based on the high-angle annular dark-field (HAADF) images shown in Supplementary Figs. 9-11. Elemental mappings in Supplementary Figs. 10 and 11 indicated a uniform distribution of Co around $\mathrm{Rh}$ particles. As the $\mathrm{Co} / \mathrm{Rh}$ ratio increased from $0: 1$ to $1: 1$ and $3: 1$, metal particle size decreased from $\sim 2.3 \mathrm{~nm}$ to $\sim 1.7 \mathrm{~nm}$ and $\sim 1.4 \mathrm{~nm}$ with a narrower distribution. The $\mathrm{CO}$ uptake values also increased from 57.6 $\mu \mathrm{mol} \mathrm{g}-1$ on $\mathrm{Rh} / \mathrm{MCM}-41$ to 78.9 and $108.1 \mu \mathrm{mol} \mathrm{g}^{-1}$ on $\mathrm{Rh}_{1} \mathrm{Co}_{1} / \mathrm{MCM}-41$ and $\mathrm{Rh}_{1} \mathrm{Co}_{3} / \mathrm{MCM}-41$, respectively. Thus, the presence of Co promoted the dispersion of the Rh particles.
In-situ X-ray absorption fine structure analysis. In-situ X-ray absorption near edge structure (XANES) and extended X-ray absorption fine structure (EXAFS) spectra of Rh K-edge and Co $\mathrm{K}$-edge were measured to explore the electronic properties and local environments under hydroformylation conditions. Referring to the XANES spectra of metal and oxides standards in Fig. $4 \mathrm{a}, \mathrm{Rh}$ in $\mathrm{Rh} / \mathrm{MCM}-41$ was slightly oxidized and it became more oxidized with the presence of Co. As shown in Fig. 4c, the EXAFS signals in $\mathrm{R}$ space indeed showed a significant peak located between $1.5-2.0 \AA$, correlating with the coordination by low- $Z$ elements (e.g., $\mathrm{C}$ or $\mathrm{O}$ ). It is difficult to distinguish the contributions from $\mathrm{Rh}-\mathrm{C}$ or $\mathrm{Rh}-\mathrm{O}$ bonds due to their similar bond length. The possibility of $\mathrm{Rh}-\mathrm{O}$ bond from bulk $\mathrm{Rh}$ oxides could be ruled out due to the lack of corresponding $\mathrm{Rh}-\mathrm{Rh}$ peaks from bulk oxides. Nevertheless, given the fine assembles from HAADF images, a Rh-O contribution from the MCM-41 substrate could not be excluded. Temperature-programmed reduction (TPR) profiles on both the mono- and bimetallic Rh-based catalysts show that besides the reduction of bulk Rh oxides at $100-110^{\circ} \mathrm{C}$, a peak located within $275-285^{\circ} \mathrm{C}$ was observed. The latter should correlate with the reduction of the Rh species interacted with the silica framework (Supplementary Fig. 12). Rh-C interaction, especially from $\mathrm{CO}$ adsorption, could also be possible due to the formation of carbonyl on the Rh surface 27,28 . Thus, the Rh-low Z peak was assigned to both of $\mathrm{Rh}-\mathrm{C}$ and $\mathrm{Rh}-\mathrm{O}$ contributions. The peak located between $2.0 \AA$ and $3.0 \AA$ was mainly associated with the $\mathrm{Rh}-\mathrm{M}$ ( $\mathrm{Rh}$ or $\mathrm{Co}$ ) bonds. With increasing $\mathrm{Co} / \mathrm{Rh}$ ratio from $0: 1$ to $1: 1$ and $3: 1$, the Rh-M peak noticeably decreased, validating the reduction of $\mathrm{Rh}$ particle size as suggested by the transmission electron microscopy (TEM) and CO chemisorption experiments. In Fig. $4 \mathrm{~b}$, the Co K-edge spectrum of $\mathrm{Co}_{3} / \mathrm{MCM}-$ 41 showed a strong white line due to the strong interaction between $\mathrm{Co}^{2+}$ and silica framework ${ }^{29}$. As shown in Fig. 4d, nearly negligible $\mathrm{Co}-\mathrm{Co}$ bond from bulk oxides was observed on the bimetallic samples, suggesting that the majority of the Co species was highly dispersed on the MCM-41 support. However, it is 

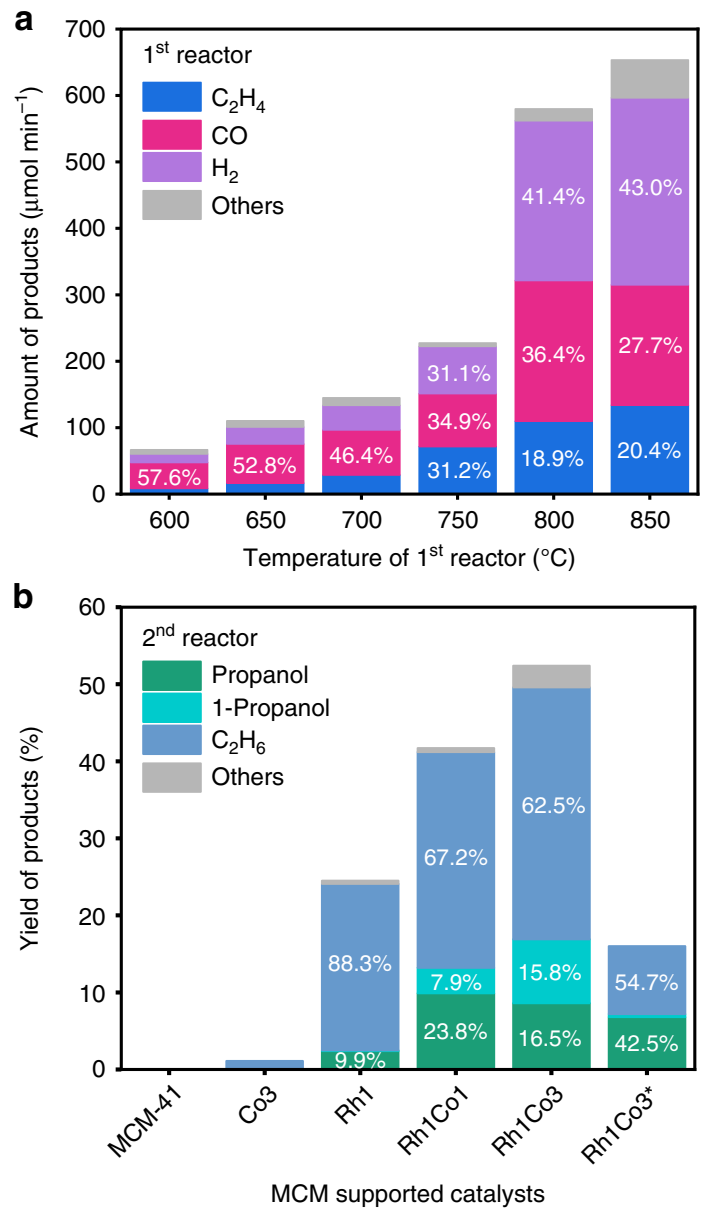

C

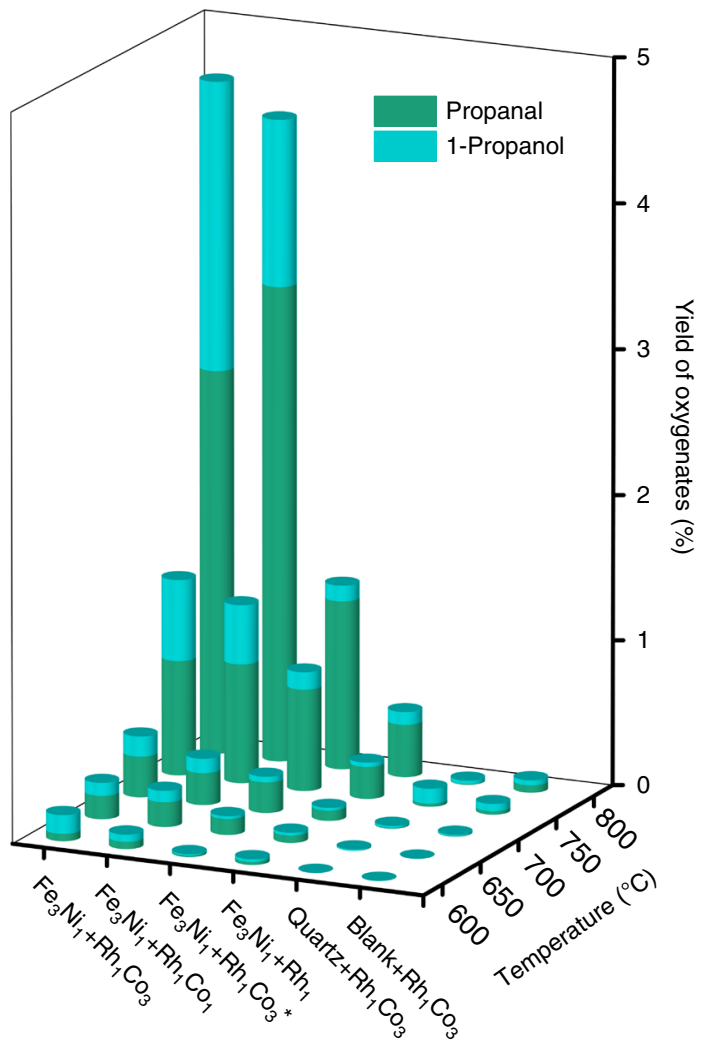

Catalysts within tandem reactor

Fig. 3 Catalytic performance of different catalysts. a Amount of products formed during the reaction of $\mathrm{CO}_{2}$ and $\mathrm{C}_{2} \mathrm{H}_{6}$ over $\mathrm{Fe}_{3} \mathrm{Ni}_{1} / \mathrm{CeO}_{2}$ at different temperatures $\left(600-850^{\circ} \mathrm{C}\right)$. b Product yield $\left(\mathrm{C}_{2} \mathrm{H}_{4}\right.$-based) of the reaction of $\mathrm{C}_{2} \mathrm{H}_{4}, \mathrm{CO}$, and $\mathrm{H}_{2}$ over the $\mathrm{MCM}-41$ supported Rh-based catalysts at $200{ }^{\circ} \mathrm{C}$. c Product yield $\left(\mathrm{C}_{2} \mathrm{H}_{6}\right.$-based) of the reaction of $\mathrm{CO}_{2}$ and $\mathrm{C}_{2} \mathrm{H}_{6}$ within the tandem reactor (first reactor: $600-800^{\circ} \mathrm{C}$, second reactor: $200{ }^{\circ} \mathrm{C}$ ). Note: the numbers within the bars of Fig. $3 a$, $b$ indicate product selectivity.

noted that the bimetallic samples showed an even stronger white line, indicating a decrease of electron density at the Fermi level that should result in weak or negligible $\mathrm{CO}$ adsorption. Therefore, the majority of Co species that strongly interacted with the silica framework ${ }^{29}$ was probably not involved in catalysis. However, given the HAADF and $\mathrm{CO}$ chemisorption results, the interaction of $\mathrm{CoO}_{x}$ species with $\mathrm{Rh}$ was most likely responsible for the increase of Rh dispersion. $\mathrm{Rh}_{1} \mathrm{Co}_{1} / \mathrm{MCM}-41$ and $\mathrm{Rh}_{1} \mathrm{Co}_{3} / \mathrm{MCM}$ 41 exhibited much higher formation rate of $\mathrm{C} 3$ oxygenates $\left(1.12 \mathrm{~min}^{-1}\right.$ and $1.04 \mathrm{~min}^{-1}$, respectively) than $\mathrm{Rh} / \mathrm{MCM}-41$ $\left(0.26 \mathrm{~min}^{-1}\right)$ by a factor of $4-5$ times. Such increase cannot be explained solely by the increase in $\mathrm{Rh}$ dispersion (1.4-1.9 times). Moreover, the 1-propanol selectivity also increased with the $\mathrm{Co} /$ $\mathrm{Rh}$ ratio. It is noted that the EXAFS fitting results of both $\mathrm{Rh}$ and Co edges (Supplementary Table 10) indicated the presence of $\mathrm{Rh}-\mathrm{Co}$ bond on the bimetallic samples. Thus, the increase of the total $\mathrm{C} 3$ formation rate and 1-propanol selectivity with the $\mathrm{Co} / \mathrm{Rh}$ ratio most likely resulted from the fraction of Co that formed bimetallic bond with Rh. To validate this hypothesis, DFT calculations were performed on the $\mathrm{Rh}$ and $\mathrm{RhCo}$ surfaces as follows.

Density functional theory calculations. The enthalpy change for ethylene hydroformylation to propanal and 1-propanol along the reaction pathways shown in Fig. 5 were calculated on $\mathrm{Rh}(111)$ and bulk-terminated- $\mathrm{Co}_{3} \mathrm{Rh}(111) \quad\left[\mathrm{Co}_{3} \mathrm{Rh}(111)\right.$ hereafter $]$ surfaces. The binding energies of involved reaction intermediates at their optimized configurations (Supplementary Fig. 13) were calculated (Supplementary Table 11) to compute the enthalpy change $(\Delta E)$ for the formation of propanal and 1-propanol on the two surfaces. The DFT calculated $\Delta E$ values along the reaction pathways as illustrated in Fig. 5 showed that the presence of Co on the RhCo bimetallic surface facilitated the formation of 1propanol due to stronger binding of oxygenate intermediates such as ${ }^{*} \mathrm{CH}_{3} \mathrm{CH}_{2} \mathrm{CHO}$ and ${ }^{*} \mathrm{CH}_{3} \mathrm{CH}_{2} \mathrm{CH}_{2} \mathrm{O}$ compared with $\mathrm{Rh}(111)$. Thus, a RhCo bimetallic catalyst with abundant surface Co sites should be expected to show higher selectivity toward 1-propanol formation in the hydroformylation reaction of $\mathrm{C}_{2} \mathrm{H}_{4}$.

Further DFT calculations were performed to determine the reaction energy $(\Delta E)$ and activation energy $\left(E_{\mathrm{a}}\right)$ of selected steps for the formation of propanal and 1-propanol. The DFT calculated $\Delta E$ and $E_{\mathrm{a}}$ for the first hydrogenation step to form ${ }^{*} \mathrm{CH}_{3} \mathrm{CH}_{2}$ were $\left(0.33\right.$ and $0.77 \mathrm{eV}$ ) and $(0.42$ and $0.68 \mathrm{eV})$ on $\mathrm{Rh}(111)$ and $\mathrm{Co}_{3} \mathrm{Rh}$ (111), respectively. The $\Delta E$ and $E_{\mathrm{a}}$ values for the second hydrogenation reaction to form propanal $\left({ }^{*} \mathrm{CH}_{3} \mathrm{CH}_{2} \mathrm{CHO}\right)$ after the formation of ${ }^{*} \mathrm{CH}_{3} \mathrm{CH}_{2} \mathrm{CO}$ via inserting ${ }^{*} \mathrm{CO}$ into ${ }^{*} \mathrm{CH}_{3} \mathrm{CH}_{2}$ were $(0.59$ and $0.82 \mathrm{eV})$ and $(0.31$ and $0.46 \mathrm{eV})$ on $\mathrm{Rh}(111)$ and $\mathrm{Co}_{3} \mathrm{Rh}(111)$, respectively. The hydrogenation of propanal $\left({ }^{*} \mathrm{CH}_{3} \mathrm{CH}_{2} \mathrm{CHO}+{ }^{*} \mathrm{H} \rightarrow{ }^{*} \mathrm{CH}_{3} \mathrm{CH}_{2} \mathrm{CH}_{2} \mathrm{O}+{ }^{*}\right)$ had $\Delta E$ and $E_{\mathrm{a}}$ values of $(0.04$ and $0.55 \mathrm{eV})$ and $(-0.29$ and $0.41 \mathrm{eV})$ on $\mathrm{Rh}(111)$ and $\mathrm{Co}_{3} \mathrm{Rh}(111)$, respectively. It was noted that the calculated $E_{\mathrm{a}}$ values for the hydrogenation reactions along reaction pathways were lower on $\mathrm{Co}_{3} \mathrm{Rh}(111)$ compared with $\mathrm{Rh}(111)$. Thus, the 

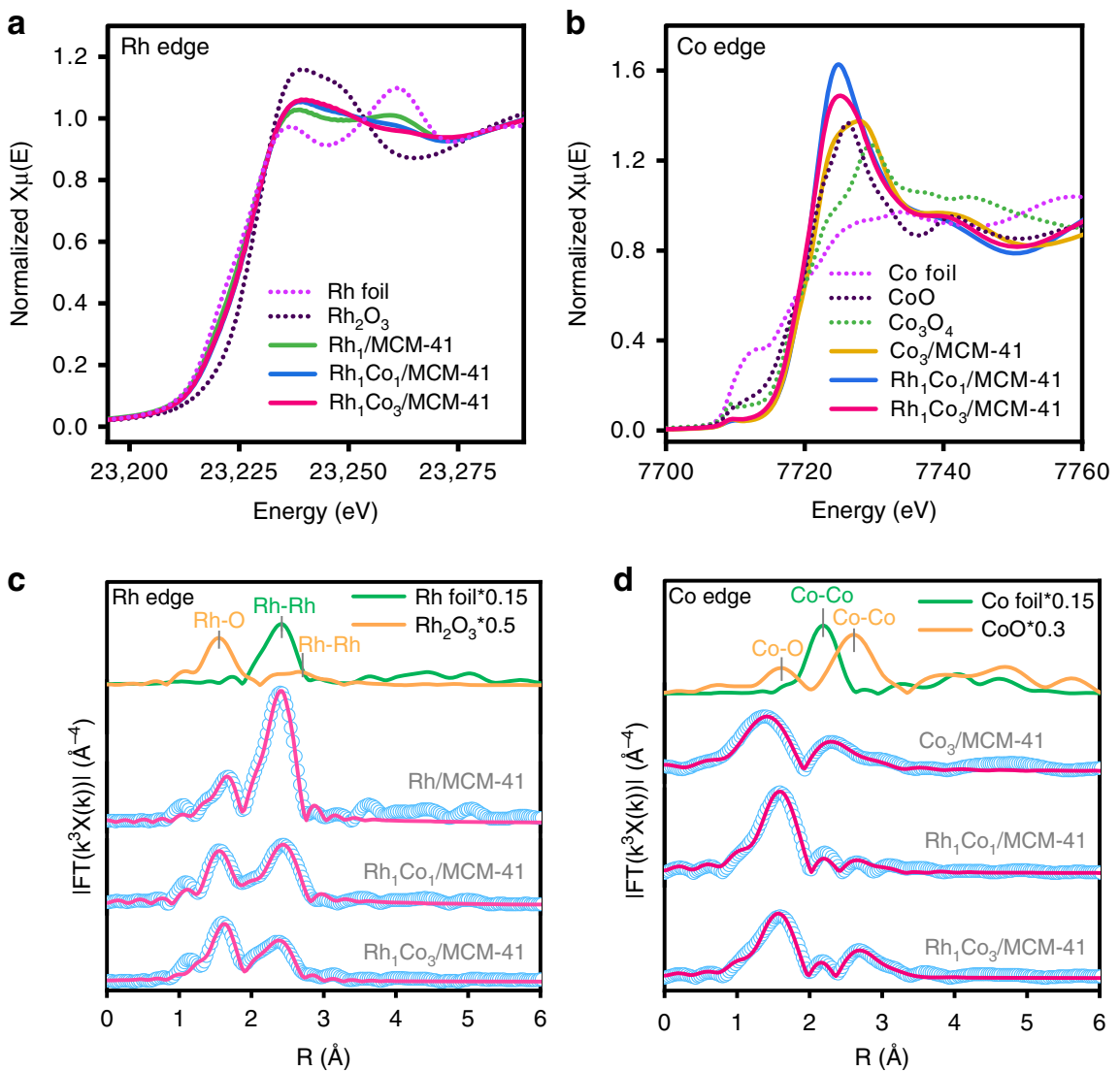

Fig. 4 Structural analyses of mono- and bimetallic $\mathbf{M C M}$-supported Rh-based catalysts. a, $\mathbf{b}$ XANES spectra of Rh and Co K-edges. c, $\mathbf{d}$ Fourier transformed EXAFS spectra (sky blue circles) and fittings (deep pink line) of Rh and Co K-edges.

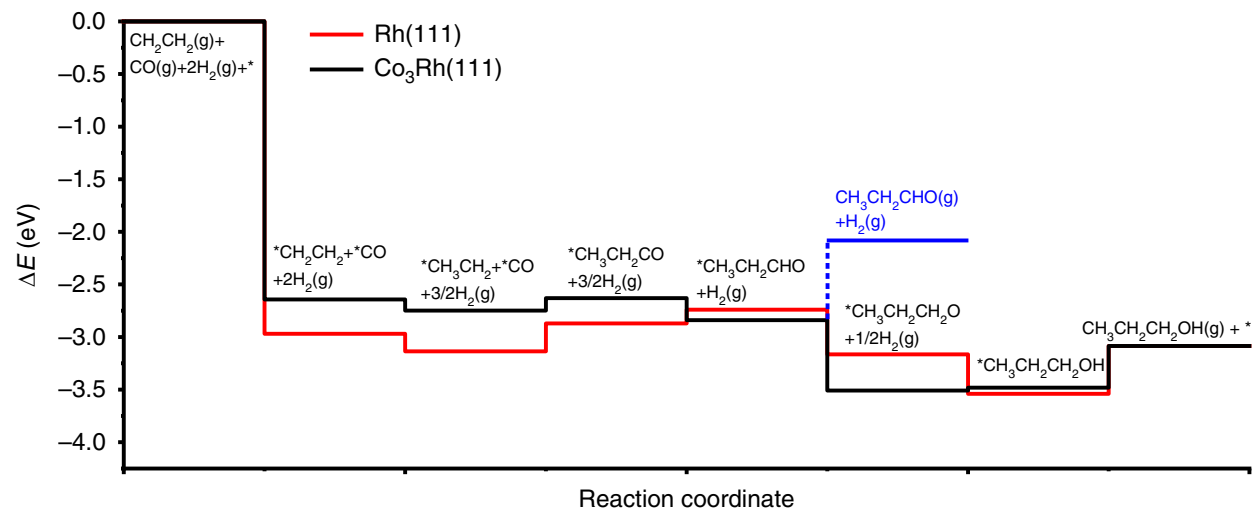

Fig. 5 DFT calculations of reaction pathways on $\mathbf{R h}(\mathbf{1 1 1})$ and $\mathbf{C O}_{3} \mathbf{R h}(\mathbf{1 1 1})$. DFT calculated energy change $(\Delta E)$ for hydroformylation into propanal and further hydrogenation into 1-propanol on monometallic Rh and bimetallic RhCo surfaces.

DFT results suggested that hydrogenation of the hydroformylation intermediates was promoted due to the presence of Co on the bimetallic surface. On $\mathrm{Rh}(111)$, the desorption of ${ }^{*} \mathrm{CH}_{3} \mathrm{CH}_{2} \mathrm{CHO}$ was uphill by $0.66 \mathrm{eV}$ (blue line) and its hydrogenation to ${ }^{*} \mathrm{CH}_{3} \mathrm{CH}_{2} \mathrm{CH}_{2} \mathrm{O}$ had an $E_{\mathrm{a}}$ of $0.55 \mathrm{eV}$, thus competing with each other. However, the entropy contribution made desorption more favorable leading to the formation of ${ }^{*} \mathrm{CH}_{3} \mathrm{CH}_{2} \mathrm{CHO}$ as the major product on $\mathrm{Rh}(111)$. In contrast, on $\mathrm{Co}_{3} \mathrm{Rh}(111)$, ${ }^{*} \mathrm{CH}_{3} \mathrm{CH}_{2} \mathrm{CHO}$ desorption was uphill by $0.76 \mathrm{eV}$ and its hydrogenation to ${ }^{*} \mathrm{CH}_{3} \mathrm{CH}_{2} \mathrm{CH}_{2} \mathrm{O}$ had an $E_{\mathrm{a}}$ of $0.41 \mathrm{eV}$. This showed that the formation of ${ }^{*} \mathrm{CH}_{3} \mathrm{CH}_{2} \mathrm{CH}_{2} \mathrm{O}$, a critical intermediate for 1propanol formation, was more favorable on $\mathrm{Co}_{3} \mathrm{Rh}(111)$ compared to $\mathrm{Rh}(111)$ due to stronger bindings of ${ }^{*} \mathrm{CH}_{3} \mathrm{CH}_{2} \mathrm{CHO}$ and ${ }^{*} \mathrm{CH}_{3} \mathrm{CH}_{2} \mathrm{CH}_{2} \mathrm{O}$ on $\mathrm{Co}_{3} \mathrm{Rh}(111)$. The hydrogenation of
${ }^{*} \mathrm{CH}_{3} \mathrm{CH}_{2} \mathrm{CH}_{2} \mathrm{O}$ to ${ }^{*} \mathrm{CH}_{3} \mathrm{CH}_{2} \mathrm{CH}_{2} \mathrm{OH}$ had $\Delta E$ of $0.63 \mathrm{eV}$ and a relatively high $E_{\mathrm{a}}$ of $1.42 \mathrm{eV}$ on $\mathrm{Co}_{3} \mathrm{Rh}(111)$, indicating that this step was potentially rate-limiting to form 1-propanol. Overall, in agreement with the experimental results, DFT calculations predicted an enhanced production of C3 oxygenates, especially 1propanol on the Rh-Co bimetallic catalysts.

\section{Discussion}

In summary, we have proposed and demonstrated a successful oxygenate production strategy enabled by inserting $\mathrm{CO}_{2}$-derived $\mathrm{CO}$ into ethane-derived ethylene using a tandem reactor (with $\mathrm{Fe}_{3} \mathrm{Ni}_{1} / \mathrm{CeO}_{2}$ and $\mathrm{RhCo}_{\mathrm{x}} / \mathrm{MCM}-41$ catalysts) at ambient pressure. The presence of Co species could not only promote oxo-synthesis activity by increasing $\mathrm{Rh}$ dispersion, but also promote $\mathrm{C} 3$ 
oxygenates formation especially 1-propanol due to favorable hydrogenation of hydroformylation intermediates on the $\mathrm{Rh}-\mathrm{Co}$ bimetallic surface. This study offers a promising way to simultaneously convert $\mathrm{CO}_{2}$ and light alkanes in shale gas into valueadded aldehydes and alcohols.

\section{Methods}

Preparation of Rh-based mono- and bimetallic catalysts. All regents were used without purification. Unless otherwise noted, all of the chemicals $\left(\mathrm{Fe}\left(\mathrm{NO}_{3}\right)_{3}\right.$. $9 \mathrm{H}_{2} \mathrm{O}, \mathrm{Ni}\left(\mathrm{NO}_{3}\right)_{2} \cdot 6 \mathrm{H}_{2} \mathrm{O}, \mathrm{Co}\left(\mathrm{NO}_{3}\right)_{2} \cdot 6 \mathrm{H}_{2} \mathrm{O}, \mathrm{Rh}\left(\mathrm{NO}_{3}\right)_{3} \cdot x \mathrm{H}_{2} \mathrm{O}, \mathrm{CeO}_{2}$, and $\mathrm{MCM}-$ 41) were purchased from Sigma Aldrich. The information of precursors, loading amount and atomic ratio were listed in Supplementary Table 1. All the catalysts were synthesized using an incipient wetness co-impregnation method over the $\mathrm{CeO}_{2}$ or MCM-41 supports with an aqueous solution of the respective metal precursors. All the catalysts were dried at $80^{\circ} \mathrm{C}$ overnight and then calcined at $290^{\circ} \mathrm{C}$ for $2 \mathrm{~h}$ with a heating ramp rate of $0.8^{\circ} \mathrm{C} \mathrm{min}^{-1}$

Characterization of catalysts. Pulse $\mathrm{CO}$ chemisorption was performed in an AMI-300ip (Altamira) instrument. As-prepared catalyst $(\sim 100 \mathrm{mg})$ was pretreated under $\mathrm{He}$ atmosphere $\left(50 \mathrm{ml} \mathrm{min}^{-1}\right)$ at $120^{\circ} \mathrm{C}$ for $30 \mathrm{~min}$ and then cooled to $30^{\circ} \mathrm{C}$. Then, the sample was heated to $200^{\circ} \mathrm{C}\left(10^{\circ} \mathrm{C} \mathrm{min}-1\right)$ and held for $1 \mathrm{~h}$ in a mixture of $10 \% \mathrm{H}_{2}$ in Ar (totally $50 \mathrm{ml} \mathrm{min}^{-1}$ ), and cooled down in $\mathrm{He}\left(50 \mathrm{ml} \mathrm{min}^{-1}\right)$ for degassing before pulsing $10 \% \mathrm{CO}$ in $\mathrm{He}(590 \mu \mathrm{L}$ loop). The amount of chemisorbed $\mathrm{CO}$ was used to estimate the number of metal active sites on the catalyst with an assumption of $\mathrm{CO} /$ metal ratio being $1: 1$.

The same AMI-300ip (Altamira) instrument was used for TPR measurements. For TPR tests, as-prepared sample $(\sim 100 \mathrm{mg})$ was pretreated under He atmosphere $\left(50 \mathrm{ml} \mathrm{min}^{-1}\right.$ ) at $120^{\circ} \mathrm{C}$ for $30 \mathrm{~min}$ and then cooled to $40^{\circ} \mathrm{C}$. TPR test was subsequently performed in a mixture of $10 \% \mathrm{H}_{2}$ in $\mathrm{Ar}$ (total $50 \mathrm{ml} \mathrm{min}^{-1}$ ) with a heating rate of $10^{\circ} \mathrm{C} \mathrm{min}-1$ to $450^{\circ} \mathrm{C}$. A thermal conductivity detector (TCD) was used to record the hydrogen consumption profile as a function of reduction temperature, allowing a quantitative comparison of the reducibility of active metals in different catalysts.

Metal particle distribution on the spent Rh-based catalysts was characterized using HAADF imaging within an FEI Talos F200X TEM (operated at $200 \mathrm{keV}$ ). Scanning TEM-energy dispersive spectroscopy mapping was performed using the same instrument. Spent samples were ultrasonically dispersed in ethanol for 10 min. Afterwards, a droplet was dripped onto lacey carbon film supported on copper grid and fully dried before use.

The in-situ XAFS experiments were carried out at beamline 8-ID (ISS) of the National Synchrotron Light Source II at Brookhaven National Laboratory. The insitu Rh K-edge $(23,220 \mathrm{eV})$ and Co K-edge $(7709 \mathrm{eV})$ XAFS spectra were collected for MCM-41 supported catalysts, as well as metal foils (Rh and $\mathrm{Co}$ ) and metal oxide standards $\left(\mathrm{Rh}_{2} \mathrm{O}_{3}, \mathrm{Co}_{3} \mathrm{O}_{4}\right.$, and $\left.\mathrm{CoO}\right)$. Approximately $100 \mathrm{mg}$ of sample $(60-80$ mesh) was loaded into a home-designed in-situ copper micro-channel reactor $^{6}$. Graphite carbon paper was used as the reactor window material for transmission and fluorescence modes. Quartz wool was packed at both sides of the sample to fix the catalyst bed. The sample was exposed to the reaction stream $\left(\mathrm{C}_{2} \mathrm{H}_{4} / \mathrm{CO} / \mathrm{H}_{2} / \mathrm{He}=3 / 3 / 3 / 3 \mathrm{ml} \mathrm{min}^{-1}\right)$ at $200{ }^{\circ} \mathrm{C}$ for $60 \mathrm{~min}$. To reduce thermal disordering contribution, the catalyst bed was cooled to room temperature under the reaction stream. About 30 scans were collected and merged as an individual spectrum to improve the signal-to-noise ratio. Between two scans, an interval time of $45 \mathrm{~s}$ was imposed for rest to reduce sample damage potentially induced by the high-flux (10 14 @10 keV) X-ray beam exposure. Data processing was preformed using the IFEFFIT package. Rh and Co foils were used as standard references to calibrate energy shift and obtain passive electron reduction factor $\left(\mathrm{S}_{0}{ }^{2}\right)$. It should be noted that the contributions from both metal and nonmetal (low- $\mathrm{Z}$ elements) neighbors were significant in the Rh spectra, which complicated the EXAFS analysis. Therefore, a similar method was adopted from ref. ${ }^{30}$, with which the residuals of the fits to the metal contribution were separately fit to approximate the low- $Z$ contribution. In addition, owing to the similarity of Rh-C and Rh-O EXAFS signals in the first nearest shell, they were treated together as the Rh-low Z interactions. Based on ref. ${ }^{30}$, the $\mathrm{Rh}-\mathrm{Rh}(\mathrm{Co})$ and $\mathrm{Rh}$-low $Z$ interactions were analyzed with the phase shifts and back-scattering amplitudes obtained from the Feff calculations of $\mathrm{Rh}$ foil and $\mathrm{Rh}_{2} \mathrm{O}_{3}$ structures, respectively. Moreover, for the $\mathrm{Rh}_{1} \mathrm{Co}_{3}\left(\mathrm{Rh}_{1} \mathrm{Co}_{1}\right)$ bimetallic samples, the EXAFS spectra of both Rh K-edge and Co K-edge were fitted simultaneously with additional constraints $\mathrm{s}^{30}$ of coordination number $(\mathrm{CN})$ relationship, bond length $(\mathrm{R})$ and structure disordering $\left(\sigma^{2}\right)$, i.e., $\mathrm{CN}_{\mathrm{Rh}-\mathrm{Co}} / \mathrm{CN}_{\mathrm{Co}-\mathrm{Rh}}=3: 1$ (or $\left.1: 1\right), \mathrm{R}_{\mathrm{Rh}-\mathrm{Co}}=\mathrm{R}_{\mathrm{Co}-\mathrm{Rh}}, \sigma_{\mathrm{Rh}-\mathrm{Co}}^{2}=\sigma^{2} \mathrm{Co-Rh}$. For Co edge, the EXAFS signals were fitted based on the information of $\mathrm{Co}$ foil and $\mathrm{CoO}$ structures.

Catalytic performance evaluation. Tandem reactor experiments were carried out within two quartz tubes ( $7 \mathrm{~mm} \mathrm{ID}, 9.6 \mathrm{~mm}$ OD) heated separately by two tandem furnaces (Thermo Scientific Lindberg/Blue M) under the atmospheric pressure. For a typical experiment, $\sim 300 \mathrm{mg}\left(\mathrm{Fe}_{3} \mathrm{Ni}_{1} / \mathrm{CeO}_{2}\right)$ and $\sim 200 \mathrm{mg}\left(\mathrm{Rh}_{1} \mathrm{Co}_{x} / \mathrm{MCM}-41\right.$, $x=0,1$, or 3$)$ of catalysts (60-80 mesh) were loaded into the first and second flow reactors, respectively. Approximately $100 \mathrm{mg}$ of acid-purified quartz particle
(60-80 mesh) was used for the dilution of each catalyst bed to reduce heat transport limitations. In prior to each reaction, the catalyst in the first reactor was pretreated under a mixture of $\mathrm{H}_{2}$ and $\mathrm{Ar}\left(5 / 5 \mathrm{ml} \mathrm{min}^{-1}\right)$ at $600{ }^{\circ} \mathrm{C}$ for $1 \mathrm{~h}$, during which process the catalyst in the second reactor was bypassed and maintained under $\mathrm{Ar}$ atmosphere. After the reduction, the catalyst bed in each reactor was heated to desired temperatures, and subsequently exposed to the reaction stream of $\mathrm{C}_{2} \mathrm{H}_{6} / \mathrm{CO}_{2} / \mathrm{Ar}\left(6 / 3 / 3 \mathrm{ml} \mathrm{min}^{-1}\right)$ at the atmospheric pressure. The outlet of the first reactor was connected immediately to the inlet of the second reactor to ensure all the effluents enter into the second reactor. In addition, the outlet gasline of the second reactor was wrapped with heating tapes at $150{ }^{\circ} \mathrm{C}$ to avoid any condensations of water vapor and oxygenates. The exhaust was analyzed by an Agilent 7890B gas chromatography (PLOT Q and MOLESEIVE columns) equipped with a thermal conductivity detector and a flame ionized detector. Single reactor experiments followed the similar procedure. Water vapor was calibrated based on oxygen balance by running the reverse water-gas shift reaction with a $\mathrm{PtCo} / \mathrm{CeO}_{2}$ catalyst at different temperatures. The element balances of carbon, hydrogen, and oxygen were $100 \pm 2 \%, 100 \pm 3$, and $100 \pm 3 \%$, respectively. Conversion $(X)$, TOF, selectivity $(S)$, and yield $(Y)$ at steady state were calculated as follows:

$$
\begin{gathered}
X_{i}=\frac{\left[F_{i}\right]_{\text {in }}-\left[F_{i}\right]_{\text {out }}}{\left[F_{i}\right]_{\text {out }}} \times 100 \% \\
\mathrm{TOF}_{i}=\left|\frac{\left[F_{i}\right]_{\text {in }}-\left[F_{i}\right]_{\text {out }}}{\text { CO uptake } \cdot m_{\text {catalyst }}}\right|
\end{gathered}
$$

where $\left[F_{i}\right]_{\text {in }}$ and $\left[F_{i}\right]_{\text {out }}$ referred to the inlet and outlet molar flow rate, respectively, of reactant $i$ corrected by the Ar molar flow rate $\left(\mathrm{mol} \mathrm{min}^{-1}\right)$; $\mathrm{CO}$ uptake $\left(\mu \mathrm{mol} \mathrm{g}{ }^{-1}\right)$ and $m_{\text {catalyst }}(\mathrm{mg})$ indicated the number of active site per unit mass of catalyst and the mass of catalyst, respectively.

The selectivity $(S)$ of carbon containing species was defined separately for the first reactor, second reactor, and tandem reactor. For the first reactor (reaction of $\mathrm{CO}_{2}$ and $\mathrm{C}_{2} \mathrm{H}_{6}, \mathrm{C}_{2} \mathrm{H}_{6}$-based selectivity),

$$
S_{i}=\frac{\left[F_{i}\right]_{\text {out }}}{\left[F_{\mathrm{C}_{2} \mathrm{H}_{6}}\right]_{\text {in }}-\left[F_{\mathrm{C}_{2} \mathrm{H}_{6}}\right]_{\text {out }}} \times \frac{n_{\text {carbon-atoms }, i}}{n_{\text {carbon-atoms, } \mathrm{C}_{2} \mathrm{H}_{6}}} \times 100 \%
$$

where the species $i$ could be $\mathrm{CO}, \mathrm{CH}_{4}, \mathrm{C}_{2} \mathrm{H}_{4}, \mathrm{C}_{3} \mathrm{H}_{6}, \mathrm{C}_{3} \mathrm{H}_{8}, \mathrm{C}_{4} \mathrm{H}_{8}, \mathrm{C}_{4} \mathrm{H}_{10} ; n$ is the number of carbon from $\mathrm{C}_{2} \mathrm{H}_{6}$ in species $i$. It should be noted that the $\mathrm{CO}$ reported here is the part produced from $\mathrm{C}_{2} \mathrm{H}_{6}$ via dry reforming reaction. Based on the oxygen balance, $S_{\mathrm{CO}}$ was calculated in the following:

$$
S_{\mathrm{CO}}=\frac{\left(\left[F_{\mathrm{CO}}\right]_{\text {out }}\right)-\left[F_{\mathrm{H}_{2} \mathrm{O}}\right]_{\text {out }} / 2}{\left[F_{\mathrm{C}_{2} \mathrm{H}_{6}}\right]_{\text {in }}-\left[F_{\mathrm{C}_{2} \mathrm{H}_{6}}\right]_{\text {out }}} \times \frac{n_{\text {carbon-atoms, } \mathrm{CO}}}{n_{\text {carbon-atoms, } \mathrm{C}_{2} \mathrm{H}_{6}}} \times 100 \%
$$

For the second reactor (reaction of $\mathrm{C}_{2} \mathrm{H}_{4}, \mathrm{CO}$, and $\mathrm{H}_{2}, \mathrm{C}_{2} \mathrm{H}_{4}$-based selectivity),

$$
S_{i}=\frac{\left[F_{i}\right]_{\text {out }}}{\left[F_{C_{2} H_{4}}\right]_{\text {in }}-\left[F_{C_{2} H_{6}}\right]_{\text {out }}} \times \frac{n_{\text {carbon-atoms }, i}}{n_{\text {carbon-atoms, } \mathrm{C}_{2} \mathrm{H}_{4}}} \times 100 \%
$$

where the species $i$ could be $\mathrm{C}_{2} \mathrm{H}_{6}, \mathrm{C}_{3} \mathrm{H}_{6}, \mathrm{C}_{3} \mathrm{H}_{8}, \mathrm{C}_{4} \mathrm{H}_{8}, \mathrm{C}_{4} \mathrm{H}_{10}, \mathrm{C}_{3} \mathrm{H}_{6} \mathrm{O}$ (propanal) and $\mathrm{C}_{3} \mathrm{H}_{8} \mathrm{O}$ (1-propanol); $n$ is the number of carbon from $\mathrm{C}_{2} \mathrm{H}_{4}$ in species $i$. Note: $n$ should be 2 for $\mathrm{C}_{3} \mathrm{H}_{6} \mathrm{O}$ and $\mathrm{C}_{3} \mathrm{H}_{8} \mathrm{O}$.

For the tandem reactor, it follows the same definition as that of the first reactor with a $\mathrm{C}_{2} \mathrm{H}_{6}$-based selectivity. Species $i$ could be $\mathrm{CO}, \mathrm{CH}_{4}, \mathrm{C}_{2} \mathrm{H}_{4}, \mathrm{C}_{3} \mathrm{H}_{6}, \mathrm{C}_{3} \mathrm{H}_{8}$, $\mathrm{C}_{4} \mathrm{H}_{8}, \mathrm{C}_{4} \mathrm{H}_{10}, \mathrm{C}_{3} \mathrm{H}_{6} \mathrm{O}$ (propanal) and $\mathrm{C}_{3} \mathrm{H}_{8} \mathrm{O}$ (1-propanol). Note: $n$ was chosen as 3 for $\mathrm{C}_{3} \mathrm{H}_{6} \mathrm{O}$ and $\mathrm{C}_{3} \mathrm{H}_{8} \mathrm{O}$

The yield $(Y)$ of carbon containing species was the product of conversion and selectivity, i.e.,

$$
Y_{i}=X_{i} \cdot S_{i}
$$

Density functional theory calculation methods. Spin polarized periodic DFT 31,32 calculations were performed using Vienna Ab-Initio Simulation Package (VASP) $\operatorname{code}^{33,34}$. Projector augmented wave potentials were used to describe the core electrons with the generalized gradient approximation ${ }^{35,36}$, using PW91 functionals ${ }^{37}$. The Kohn-Sham one-electron wave functions were expanded by using a plane wave basis set with a kinetic energy cutoff of $400 \mathrm{eV}$. The Brillouin zone was sampled using a $3 \times 3 \times 1 k$-point grid in the Monkhorst-Pack scheme $e^{38}$.

The $\mathrm{Rh}(111)$ surface was modeled using a four layer $4 \times 4$ surface slab. The bulk-terminated $\mathrm{Co}_{3} \mathrm{Rh}(111)$ surface was cleaved using a $\mathrm{L}_{12}-\mathrm{Co}_{3} \mathrm{Rh}$ cubic crystal structure. A $15 \AA$ thick vacuum was added along the direction perpendicular to the surface in the initial slab model to avoid the artificial interactions between the slab and its periodic images. During geometry optimization, the atoms in the top two layers were allowed to relax while the atoms in the bottom two layers were fixed. Ionic positions were optimized until Hellman-Feynman force on each ion was smaller than $0.02 \mathrm{eV} / \mathrm{A}$.

The binding energy (BE) of an adsorbate is calculated as:

$$
\mathrm{BE}_{\text {adsorbate }}=\mathrm{E}_{\text {slab+adsorbate }}-\mathrm{E}_{\text {slab }}-\mathrm{E}_{\text {adsorbate }}
$$

where $E_{\text {slab }+ \text { adsorbate, }} E_{\text {slab }}$, and $E_{\text {adsorbate }}$ are the total energies of slab with adsorbate, clean slab, and adsorbate species in gas phase, respectively. 
The transition state of a chemical reaction was located using the climbing image nudged elastic band method implemented in VASP ${ }^{39}$. The activation energy $\left(E_{\mathrm{a}}\right)$ of a chemical reaction is defined as the energy difference between the initial and transition states.

\section{Data availability}

The data that support the findings of this study are available from the corresponding authors upon reasonable request.

Received: 11 October 2019; Accepted: 30 March 2020;

Published online: 20 April 2020

\section{References}

1. Rekker, S. A., O’Brien, K. R., Humphrey, J. E. \& Pascale, A. C. Comparing extraction rates of fossil fuel producers against global climate goals. Nat. Clim. Change 8, 489-492 (2018).

2. Rogelj, J., Forster, P. M., Kriegler, E., Smith, C. J. \& Séférian, R. Estimating and tracking the remaining carbon budget for stringent climate targets. Nature 571, 335-342 (2019).

3. Turner, P. A., Field, C., Lobell, D. B., Sanchez, D. \& Mach, K. Unprecedented rates of land-use transformation in modelled climate change mitigation pathways. Nat. Sustain 1, 240-245 (2018).

4. Thomas, M., Partridge, T., Harthorn, B. H. \& Pidgeon, N. Deliberating the perceived risks, benefits, and societal implications of shale gas and oil extraction by hydraulic fracturing in the US and UK. Nat. Energy 2, 1-7 (2017).

5. Boudet, H. S. Public perceptions of and responses to new energy technologies. Nat. Energy 4, 446-455 (2019).

6. Yan, B. et al. Active sites for tandem reactions of $\mathrm{CO}_{2}$ reduction and ethane dehydrogenation. Proc. Natl Acad. Sci. USA 115, 8278-8283 (2018).

7. Gomez, E. et al. Combining $\mathrm{CO}_{2}$ reduction with propane oxidative dehydrogenation over bimetallic catalysts. Nat. Commun. 9, 1-6 (2018)

8. Xie, Z. et al. Effects of oxide supports on the $\mathrm{CO}_{2}$ reforming of ethane over Pt-Ni bimetallic catalysts. Appl. Catal. B. Environ. 245, 376-388 (2019).

9. Sullivan, M. M. \& Bhan, A. Effects of oxygen coverage on rates and selectivity of propane- $\mathrm{CO}_{2}$ reactions on molybdenum carbide. J. Catal. 357, 195-205 (2018).

10. Zhang, R. et al. Photocatalytic oxidative dehydrogenation of ethane using $\mathrm{CO}_{2}$ as a soft oxidant over $\mathrm{Pd} / \mathrm{TiO}_{2}$ catalysts to $\mathrm{C}_{2} \mathrm{H}_{4}$ and syngas. ACS Catal. 8, 9280-9286 (2018).

11. Porosoff, $\mathrm{M}$. D. et al. Identifying different types of catalysts for $\mathrm{CO}_{2}$ reduction by ethane through dry reforming and oxidative dehydrogenation. Angew. Chem. Int. Ed. 54, 15501-15505 (2015).

12. Nowicka, E. et al. Elucidating the role of $\mathrm{CO}_{2}$ in the soft oxidative dehydrogenation of propane over ceria-based catalysts. ACS Catal. 8, 3454-3468 (2018).

13. Ramirez, A. et al. Effect of zeolite topology and reactor configuration on the direct conversion of $\mathrm{CO}_{2}$ to light olefins and aromatics. ACS Catal. $\mathbf{9}$, 6320-6334 (2019).

14. Gomez, E., Nie, X., Lee, J. H., Xie, Z. \& Chen, J. G. Tandem reactions of $\mathrm{CO}_{2}$ reduction and ethane aromatization. J. Am. Chem. Soc. 141, 17771-17782 (2019).

15. Market Research Future. Aldehyde Market Research Report-Global Forecast Till 2025. https://www.marketresearchfuture.com/reports/aldehyde-market2356 (2019).

16. Market Research Future. Industrial Alcohol Market Research Report-Forecast to 2023. https://www.marketresearchfuture.com/reports/industrial-alcoholmarket-5787 (2019).

17. Cornils, B., Herrmann, W. A. \& Rasch, M. Otto Roelen, pioneer in industrial homogeneous catalysis. Angew. Chem. Int. Ed. 33, 2144-2163 (1994).

18. Dingwall, P. et al. Understanding a hydroformylation catalyst that produces branched aldehydes from alkyl alkenes. J. Am. Chem. Soc. 139, 15921-15932 (2017).

19. Pandey, S. et al. Iron catalyzed hydroformylation of alkenes under mild conditions: evidence of an Fe(II) catalyzed process. J. Am. Chem. Soc. 140, 4430-4439 (2018).

20. Iu, L., Fuentes, J. A., Janka, M. E., Fontenot, K. J. \& Clarke, M. L. High iso aldehyde selectivity in the hydroformylation of short-chain alkenes. Angew. Chem. Int. Ed. 58, 2120-2124 (2019).

21. Börner A, Franke R. Hydroformylation: fundamentals, processes, and applications in organic synthesis (John Wiley \& Sons, 2016).
22. Franke, R., Selent, D. \& Börner, A. Applied hydroformylation. Chem. Rev. 112, 5675-5732 (2012).

23. Grant, J. T. et al. Selective oxidative dehydrogenation of propane to propene using boron nitride catalysts. Science 354, 1570-1573 (2016).

24. Gao, Y. et al. Recent advances in intensified ethylene production-a review. ACS Catal. 9, 8592-8621 (2019).

25. Wang, L. et al. Atomic-level insights in optimizing reaction paths for hydroformylation reaction over $\mathrm{Rh} / \mathrm{CoO}$ single-atom catalyst. Nat. Commun. 7, 1-8 (2016).

26. Lang, R. et al. Hydroformylation of olefins by a rhodium single-atom catalyst with activity comparable to $\mathrm{RhCl}\left(\mathrm{PPh}_{3}\right)_{3}$. Angew. Chem. Int. Ed. 55, 16054-16058 (2016).

27. Yates, J. Jr., Duncan, T., Worley, S. \& Vaughan, R. Infrared spectra of chemisorbed CO on Rh. J. Chem. Phys. 70, 1219-1224 (1979).

28. Rice, C., Worley, S., Curtis, C., Guin, J. \& Tarrer, A. The oxidation state of dispersed $\mathrm{Rh}$ on $\mathrm{Al}_{2} \mathrm{O}_{3}$. J. Chem. Phys. 74, 6487-6497 (1981).

29. Ciuparu, D. et al. Mechanism of cobalt cluster size control in Co-MCM-41 during single-wall carbon nanotubes synthesis by $\mathrm{CO}$ disproportionation. $J$. Phys. Chem. B 108, 15565-15571 (2004).

30. Frenkel, A. I. Applications of extended X-ray absorption fine-structure spectroscopy to studies of bimetallic nanoparticle catalysts. Chem. Soc. Rev. 41, 8163-8178 (2012).

31. Hohenberg, P. \& Kohn, W. Inhomogeneous electron gas. Phys. Rev. 136, B864 (1964).

32. Kohn, W. \& Sham, L. J. Self-consistent equations including exchange and correlation effects. Phys. Rev. 140, A1133-A1138 (1965).

33. Kresse, G. \& Furthmüller, J. Efficiency of ab-initio total energy calculations for metals and semiconductors using a plane-wave basis set. Comp. Mater. Sci. 6, 15-50 (1996).

34. Kresse, G. \& Hafner, J. Ab initio. Phys. Rev. B 48, 13115-13118 (1993).

35. Blöchl, P. E. Projector augmented-wave method. Phys. Rev. B 50, 17953-17979 (1994).

36. Kresse, G. \& Joubert, D. From ultrasoft pseudopotentials to the projector augmented-wave method. Phys. Rev. B 59, 1758-1775 (1999).

37. Perdew, J. P. \& Wang, Y. Pair-distribution function and its coupling-constant average for the spin-polarized electron gas. Phys. Rev. B 46, 12947-12954 (1992).

38. Monkhorst, H. J. \& Pack, J. D. Special points for Brillouin-zone integrations. Phys. Rev. B 13, 5188-5192 (1976).

39. Henkelman, G. A climbing image nudged elastic band method for finding saddle points and minimum energy paths. J. Chem. Phys. 113, 9901-9904 (2000).

\section{Acknowledgements}

We acknowledge support of this work by the U.S. Department of Energy (DOE), Office of Basic Energy Sciences, Catalysis Science Program, under contract number DESC0012704. This research used resources of the Center for Functional Nanomaterials and beamline 8-ID (ISS) of the National Synchrotron Light Source II, US Department of Energy (DOE) Office of Science User Facilities, at Brookhaven National Laboratory under contract number DE-SC0012704.

\section{Author contributions}

Z.X., Y.X., and M.X. contributed equally to this work. Z.X., Y.X., M.X., and J.G.C. designed the experiments. Z.X. synthesized the catalysts and carried out the characterizations and catalytic performance evaluations. Z.X., Y.X., M.X., and E.S. conducted the synchrotron experiments. X.C. performed the TEM and STEM imaging. Z.X. and J.H.L analyzed the XAFS data. S.K. conducted the DFT calculations. Z.X., S.K., and J.G.C. wrote the paper and J.G.C. supervised the whole project.

\section{Competing interests}

The authors declare no competing interests.

\section{Additional information}

Supplementary information is available for this paper at https://doi.org/10.1038/s41467 020-15849-x.

Correspondence and requests for materials should be addressed to S.K. or J.G.C.

Peer review information Nature Communications thanks Anne M. Gaffney and the other, anonymous, reviewer(s) for their contribution to the peer review of this work.

Reprints and permission information is available at http://www.nature.com/reprints

Publisher's note Springer Nature remains neutral with regard to jurisdictional claims in published maps and institutional affiliations. 
(c) (i) Open Access This article is licensed under a Creative Commons Attribution 4.0 International License, which permits use, sharing, adaptation, distribution and reproduction in any medium or format, as long as you give appropriate credit to the original author(s) and the source, provide a link to the Creative Commons license, and indicate if changes were made. The images or other third party material in this article are included in the article's Creative Commons license, unless indicated otherwise in a credit line to the material. If material is not included in the article's Creative Commons license and your intended use is not permitted by statutory regulation or exceeds the permitted use, you will need to obtain permission directly from the copyright holder. To view a copy of this license, visit http://creativecommons.org/ licenses/by/4.0/.

(C) The Author(s) 2020 